\title{
Prevalence Rates of Chlamydia Trachomatis and Other Sexually Transmitted Organisms in Infertile Couples Attending a Tertiary Medical Centre in Malaysia
}

\author{
Umi Kalsom $A^{a}$, Suvra $B^{a}$, Zainul RMR $R^{b}$, Siti Norlia $O^{a}$, Zalina $I^{a}$, Anita $S^{a}$ \\ ${ }^{a}$ Department of Medical Microbiology \& Immunology UKM Medical Centre, 56000, Cheras, Kuala Lumpur, \\ Malaysia \\ ${ }^{\mathrm{b}}$ Reproductive Centre UKM Medical Centre, Jalan Yaacob Latif, 56000, Cheras, Kuala Lumpur, Malaysia
}

ABSTRACT

INTRODUCTION: Chlamydia trachomatis (CT), Neisseria gonorrhoeae (NG), Trichomonas vaginalis (TV) and Mycoplasma genitalium (MG) infections are well recognized and prevalent sexually transmitted infections (STIs). The role of Mycoplasma spp and Ureaplasma spp are still controversial as some are commensals of genitourinary tract. OBJECTIVES: To estimate the prevalence rate of 7 organisms: Chlamydia trachomatis, Neisseria gonorrhoea, Mycoplasma genitalium, Trichomonas vaginalis, Mycoplasma hominis, Ureaplasma urealyticum (UU) and Ureaplasma parvum (UP) in infertile married couples during infertility evaluation. MATERIALS \& METHODS: A total of 274 samples from all of the 137 couples who attended the reproductive center from June to December 2014 were collected. Detection of the organisms was performed using multiplex polymerase chain reaction. RESULTS: STI-associated organisms were detected in $35.4 \%(97 / 274)$ of subjects. The prevalence rates of CT, MG, TV, UU, MH were $7.3 \%, 1.1 \%, 0.4 \%, 5.4 \%$ and $5.1 \%$ respectively. Twenty-one (7.7\%) subjects were positive for more than one organism. 24/274 (8.8\%) of subjects had history of urogenital tract-related symptoms and 50\% (12/24) were tested positive to one or more organisms. The presence of symptoms in both male and female subjects were found to be $10 \%(2 / 20)$ in CT infection, $10 \%$ (7/67) in UP, $14 \%(2 / 14)$ in $M H$ and $13 \%(2 / 15)$ in UU infections. CONCLUSION: Sexually transmitted organisms were detected in one third of subjects planning for fertility evaluation. The absence of symptom in most subjects particularly in $\mathrm{CT}$ infection emphasizes the need for microbiological screening during infertility evaluation. The presence of genital ureaplasmas and mycoplasmas in infertile couples should not be neglected. There is a growing need to clarify whether their roles are simply colonizers or pathogens implicated in infertility.

KEYWORDS: Infertility, sexually transmitted infections, multiplex polymerase chain reaction

\section{INTRODUCTION}

Sexually transmitted diseases were long recognized as one of the factors affecting human infertility.

\section{Corresponding Author:}

Dr. Umi Kalsom @ Satariah Ali

Department of Medical Microbiology \& Immunology, Level 16, Pre-Clinical Building, UKM Medical Centre, 56000 , Cheras, Kuala Lumpur, Malaysia

Tel No : $+6019-4264004$

Email : satariah@ppukm.ukm.edu.my
Infections such as Chlamydia trachomatis infection and gonorrhoea are known to cause alterations in female and male genital tracts. A few other organisms such as Trichomonas vaginalis, Mycoplasma spp and Ureaplasma spp are recently drawing interest of researchers in the field of infertility.

Chlamydia trachomatis, now the leading cause of bacterial sexually transmitted infections worldwide, 
mostly causes asymptomatic infection in both males and females. ${ }^{1}$ Untreated infection may allow the bacteria to ascend to the upper part of female reproductive tract, causing functional and structural damage of the fallopian tube and tubal related infertility as a consequence. ${ }^{2}$

Neisseria gonorrhoeae, discovered in 1879 by Albert Neisser is the causative agent of gonorrhoea, an ancient disease that persists until today. This obligate human pathogen causes genitourinary infections such as urethritis, orchitis and epididymitis in males, where the infections may cause urethral strictures leading to impairment of urogenital tract function. ${ }^{3}$ In females, most infections are silent or cause only mild symptoms. Thus, untreated, such infections may ascend to the upper genital tract causing pelvic inflammatory disease with infertility as a sequela. ${ }^{1}$

Trichomoniasis is a genitourinary infection caused by the protozoa Trichomonas vaginalis. Although reported prevalence in some country such as Malaysia is low, ${ }^{4}$ it is a common non-viral STI in many countries. ${ }^{5}$ This disease remained poorly diagnosed and high in prevalence despite being curable. Ureaplasma and Mycoplasma on the other hand, are commonly found in healthy women. ${ }^{6}$ These species are now recognized as emerging sexually transmitted organisms as their role in early pregnancy loss, stillbirths and neonatal morbidity has been described. ${ }^{7}$

With the exception of $N$. gonorrhoeae, most of the STIs organisms such as $C$. trachomatis, $T$. vaginalis Mycoplasmas and Ureaplasmas are difficult to culture in the routine hospital laboratory. However, the availability of non-culture-based test such as nucleic acid amplification test (NAAT) has allowed further studies on these organisms. The investigations of infectious diseases during infertility evaluations include serology tests for human immunodeficiency virus (HIV), hepatitis B virus, hepatitis C virus, rubella and syphilis. Commonly, STIs such as Chlamydia trachomatis and Neisseria gonorrhoeae infections are looked for only in patients with symptoms of urogenital tract infection whereas ureaplasmas, mycoplasmas and Trichomonas vaginalis are commonly not evaluated.

This study was conducted with the aim to determine the percentage prevalence rates of Chlamydia trachomatis, Neisseria gonorrhoeae, Trichomonas vaginalis, Mycoplasma genitalium, Mycoplasma hominis, Ureaplasma urealyticum, and Ureaplasma parvum in couples with infertility using multiplex real-time polymerase chain reaction. Other sexually transmitted organisms such as HIV, Treponema pallidum and Gardnarella vaginalis (causing bacterial vaginosis) may have a role in infertility, ${ }^{8,9}$ however, the assessment of these organisms are beyond the scope of this study.

\section{MATERIALS AND METHOD}

\section{Study design and population}

This is a descriptive, cross-sectional study conducted over a period of 7 months among the couples attending the Reproductive Centre for infertility evaluation from June to December 2014. During the study period, 137 couples attended and all were recruited. Each couple was counseled together by the attending doctor who explained about the seven sexually transmitted organisms and the infections they caused. The participants were also provided with fact sheets of information regarding each infection, its transmission, symptoms and signs, diagnosis and treatment. A written informedconsent were taken for each participant. Data collection sheet in the form of questionnaire stating symptoms of STI, previous history or treatment of STIs as well as patients' medical record were used to obtain demographic data and clinical information of STIs. Regular infectious disease screening tests such as hepatitis B surface antigen ( $\mathrm{HbsAg}$ ), rapid plasma 
reagin (RPR) for syphilis and HIV antigen/antibody tests were performed in most female subjects but the information regarding these tests were not included in this study.

\section{Sample size}

Previous studies on prevalence of sexually transmitted organisms in Malaysia were mostly done on Chlamydia trachomatis in high risk groups or in patients attending genito-urinary clinic. Hence, we decided to use the prevalence of CT in female in Genito-urinary Clinic in Malaysia (Norashikin et al. 2007), ${ }^{14}$ with $17.5 \%$ prevalence.

Using the sample size calculation formula for prevalence study by Kish L. 1965, whereby sample size $n=\left(Z_{1-\alpha}\right)^{2}\left(P(1-P) / D^{2}\right)$, with the prevalence of positive identification $\mathrm{P}=0.175$, and absolute precision (D) of $5 \%$, ie $D=0.05$, the total sample calculated is 221 . Due to budget limitation, we collected 137 samples from female subjects and 137 samples from their male partners, which amounted to 274 samples.

\section{Specimen collection}

Endocervical swab specimens were collected from female patients by the attending doctors using a manufactured collection kit, eNat ${ }^{\circledR}$ (Copan Italia S.P.A, Italy). The kit contains a swab and guanidine thyocianate based medium which stabilizes RNA and DNA of viruses, bacteria, Chlamydia, Trichomonas vaginalis and Mycoplasma and was validated for molecular assay formats. The male patients were asked to provide first-voided urine (at least 2 hours after previous urination) in a sterile $50 \mathrm{ml}$ screw-cap plastic container. After collection, the specimens were put immediately into a cooler box and transported to microbiology laboratory. Specimens received out of working hours were kept in $4^{\circ} \mathrm{C}$ in the refrigerator and processed the next working day.

\section{Specimen processing}

The swab specimens were equilibrated to room temperature and mixed by vortexing. The caps from the specimen tubes were removed carefully to avoid contamination. Excess mucus in the specimen was removed by collecting in on the swab. One $\mathrm{ml}$ specimen was transferred to $1.5-\mathrm{ml}$ microcentrifuge tubes and the tubes were centrifuged at $5000 \times \mathrm{g}$ $(7,500 \mathrm{rpm})$ for 10 minutes. The supernatant was discarded and the pellet was re-suspended in $1000 \mu \mathrm{L}$ of $1 \times$ phosphate-buffered saline (PBS) by vortex.

The urine specimens were equilibrated to room temperature and $1 \mathrm{ml}$ specimen was transferred to $1.5-\mathrm{ml}$ microcentrifuge tubes. The urine specimens were then centrifuged at 15,000 x g (13,000 rpm) for 15 minutes, as per manufacturer's protocol. Similar centrifugation speed has also been decribed. ${ }^{10}$ The urine samples required higher and longer centrifuge speed and time to ensure collection of as many cells possible in the samples. Afterwards, the supernatant was discarded and the pellet was re-suspended in 1 $\mathrm{ml}$ of $1 \times$ PBS by vortexing.

\section{DNA extraction}

The DNA was extracted from the processed specimens (swab or urine) using the StarMag 96 tissue kit (Seegene, Seoul, Korea), in accordance with the manufacturer's instructions in automated DNA extraction system called Nimbus IVD (Hamilton). The PCR mastermix was prepared by Nimbus, and sample and negative control were loaded into the mastermix by Nimbus. This system is used to prevent carry-over contamination in DNA extraction process. An internal control (IC) provided within the manufactured detection kit was added to the samples as an exogenous whole process control, immediately before the DNA extraction. The presence of internal control is to confirm the success of the extraction steps and also to monitor for any presence of inhibitor which can affect the PCR process. ${ }^{11}$ 
Multiplex real-time PCR (Anyplex ${ }^{\text {TM }} / /$ STI-7 Detection Kit)

Real-time PCR amplification for seven microorganisms (C. trachomatis, $N$. gonorrhoeae, $T$. vaginalis, M. genitalium, M. hominis, U. urealyticum, and $U$. parvum) was performed using the Anyplex ${ }^{T M}$ II STI-7 Detection Kit (Seegene, Seoul, Korea), in accordance to the manufacturer's protocol. This assay utilizes the tagging oligonucleotide cleavage and extension technology (TOCE ${ }^{T M}$ ) which has the ability to detect the seven microorganisms simultaneously in a single fluorescent channel on real -time PCR platform using melt-curve analysis. In melt -curve analysis, issues in accuracy and reproducibility may occur due to the temperature differences among DNA that has high sequence variation. The TOCE ${ }^{T M}$ technology however was designed to be not affected by sequence variation, in which it was able to produce consistent melting temperature $(\mathrm{Tm}) .{ }^{11}$ The assay was performed in a CFX96 ${ }^{\mathrm{TM}}$ Real- time thermocycler (Bio-Rad, Hercules, CA, USA). Each PCR was performed in $5 \mu \mathrm{L}$ of extracted DNA, 4x STI-7 TOM, and Anyplex PCR Mix in a $20 \mu \mathrm{L}$ reaction. Five $\mu \mathrm{L}$ of RNase-free water and 5 $\mu \mathrm{L}$ of STI-7 PC were used as negative control and positive control respectively. Results and analysis and interpretation were provided by Seegene Viewer software.

\section{STATISTICAL ANALYSIS}

Data were analysed using descriptive statistical methods (chi-square test) in SPSS software (version 22) and $p<0.05$ was considered statistically significant. Kappa (k) statistics proposed by Landis and Koch (1977) was used to assess the agreement between the detection of $C$. trachomatis, $U$. urealyticum, U. parvum and M. hominis in husband and wife. ${ }^{12}$ Guidelines for the interpretation of $k$ were as follows: $k<0.20$ indicating poor agreement; $\mathrm{k}=$ 0.21-0.40 indicating fair agreement; $\mathrm{k}=0.41-0.60$, moderate agreement; $k=0.61-0.80$, good agreement; and $\mathrm{k}=0.81-1.00$ indicating very good agreement. The study protocol was approved by the Research Ethics Committee of the Universiti Kebangsaan Malaysia Medical Centre.

\section{RESULTS}

A total of 274 samples from all of the 137 couples who attended the Reproductive Centre from June 2014 to December 2014 for infertility evaluations were collected and analysed in this study. Organisms were detected in $35.4 \%(97 / 274)$ of subjects (Table I).

More than $60 \%$ of the subjects were Malay, followed by Chinese (26\%), Indian (10\%) and others $(4 \%)$ who were mainly from Vietnam, Nigeria and Thailand. Only one female gave history of previous chlamydial infection, however, she was found to be negative for any of the tested organism. A statistically significant correlation was seen between female gender and infections $(p=0.001)$. No statistical association was found between age group, race, symptoms of urogenital tract infection and history of STIs.

The general prevalence of all detected organisms was shown in Table II. The prevalence of C. trachomatis, M. genitalium, $T$. vaginalis, $U$. urealyticum, $M$. hominis were $7.3 \%, 1.1 \%, 0.4 \%, 5.4 \%, 5.1 \%$ respectively and Ureaplasma parvum showed the highest prevalence of $24.4 \%$. C. trachomatis detection in both female and male subjects was $10.9 \%$ \& $3.6 \%$ respectively. All detected organisms were found more prevalent in female genital tract than that of male. No M. genitalium was detected in male partners of infertile couples. No Neisseria gonorrhoea was detected in this study.

Among the coupled partners, four organisms were detected in both husband and wife. Ureaplasma parvum was detected in 18/137 couples (13\%), C. trachomatis in $3 / 137$ couples $(2.2 \%)$, M. hominis in 
Table I: Characteristics of infertile couples attending reproductive centre

\begin{tabular}{|c|c|c|c|c|}
\hline Categories & $\begin{array}{c}\text { Positive }(\%) \text { for tested } \\
\text { organisms* }\end{array}$ & $\begin{array}{c}\text { Negative(\%) for tested } \\
\text { organisms* }\end{array}$ & Total & $P$ value \\
\hline Age group & & & & 0.336 \\
\hline$<35$ years & $62(22.6 \%)$ & $103(37.5 \%)$ & 165 & \\
\hline$\geq 35$ years & $35(12.8 \%)$ & $74(27.1 \%)$ & 109 & \\
\hline Race & & & & 0.978 \\
\hline Malay & $60(21.9 \%)$ & $107(39.1 \%)$ & 167 & \\
\hline Chinese & $24(8.8 \%)$ & $47(17.2 \%)$ & 71 & \\
\hline Indians & $9(3.3 \%)$ & 17 (6.2\%) & 26 & \\
\hline Others & $4(1.5 \%)$ & $6(2.2 \%)$ & 10 & \\
\hline Gender & & & & 0.001 \\
\hline Female & $66(48.1 \%)$ & $71(51.8 \%)$ & 137 & \\
\hline Male & $31(22.6 \%)$ & $106(77.4 \%)$ & 137 & \\
\hline $\begin{array}{l}\text { Presence of Symp- } \\
\text { toms** }\end{array}$ & & & & 0.117 \\
\hline Yes & $12(4.4 \%)$ & $12(4.4 \%)$ & $24 / 274$ & \\
\hline No & $85(31 \%)$ & $165(60.2 \%)$ & $250 / 274$ & \\
\hline History of STIs & & & & 0.176 \\
\hline Yes & 0 & $1(0.36 \%)$ & 1 & \\
\hline No & $97(35.4 \%)$ & $176(64.23 \%)$ & 273 & \\
\hline
\end{tabular}

$*=$ C. trachomatis $(C T), T$. vaginalis (TV), M. genitalium (MG), U. urealyticum (UU), M. hominis (MH) and U. parvum (UP)

**Symptoms: pelvic pain, dysuria, per vaginal discharge ( $p / v$ discharge), pelvic pain with $p / v$ discharge, dysuria with $\mathrm{p} / \mathrm{v}$ discharge /pelvic pain

$2 / 137$ couples $(1.5 \%)$, and $U$. urealyticum in $3 / 137$ trachomatis with $T$. vaginalis. Dual detection of couples $(2.2 \%)$. We calculated $k$ value to see the other organisms (UP+UU, $M H+U U, M G+U P)$ were also agreement between positive individuals and their seen. One male and 1 female subjects were positive partners for detected organisms (reference in for 3 organisms.

statistical analysis section). Fair agreement $(k=0.21$ -

0.40) was noted between husband and wife for $U$. A total of $8.8 \%(24 / 274)$ of male and female subjects parvum (0.406), C. trachomatis (0.259), M. hominis had history of symptoms. Among them, 50\% (12/24) $(0.260)$ and $U$. urealyticum $(0.369)$. were found to be positive for organisms (Table IV). In female subjects, pelvic pain was reported by $29 \%$ Table III shows the numbers of subjects harbouring (7/24) of the individuals and 5 of them were positive more than one organisms. In total, 21/274 (7.66\%) of for organisms. Dysuria was reported in 1 male and 1 subjects were positive for more than one organism. female with U. parvum detected in both. Other This finding was more common in females $(6.9 \%)$ than symptoms were per vaginal discharge $(20 \%)$, pelvic in males $(0.7 \%)$. Among the subjects harbouring more pain with per vaginal discharge $(12.5 \%)$, dysuria with than one organisms, 2 different species were per vaginal discharge, and dysuria with pelvic pain. detected in 19 individuals and 3 different species $U$. parvum was the most prevalent organism in were detected in the remaining two individuals. Dual symptomatic individuals $41 \%(5 / 12)$. In general, in detection of $C$. trachomatis and $U$. parvum was most both male and female subjects, symptoms were common (2.2\%) followed by $M$. hominis with reported in $10 \%(2 / 20)$ of CT infection, $10 \%(7 / 67)$ of U.parvum (1.8\%) and U. urealyticum with U.parvum UP, $14 \%(2 / 14)$ of $M H$ and $13 \%(2 / 15)$ of UU infections. $(1.1 \%)$. One woman was found positive for $C$.

Vice-versa, these findings showed that majority of the subjects with infections were asymptomatic. 
Table II: Total distributions of detected organisms

\begin{tabular}{lcccccc}
\hline & \multicolumn{2}{c}{ Female } & $(\mathrm{n}=137)$ & \multicolumn{2}{c}{ Male $(\mathrm{n}=137)$} & \multicolumn{2}{c}{ Total $(\mathrm{n}=274)$} \\
& Detected & $(\%)$ & Detected & $(\%)$ & Detected & $(\%)$ \\
\hline U. parvum & 44 & 32.1 & 23 & 16.8 & 67 & 24.4 \\
C. trachomatis & 15 & 10.9 & 5 & 3.6 & 20 & 7.3 \\
U. urealyticum & 10 & 7.3 & 5 & 3.6 & 15 & 5.4 \\
M. hominis & 11 & 8 & 3 & 2.2 & 14 & 5.1 \\
M. genitalium & 3 & 2.2 & 0 & 0 & 3 & 1.1 \\
$T$. vaginalis & 1 & 0.7 & 0 & 0 & 1 & 0.4 \\
\hline Total & 84 & 61.2 & 36 & 26.2 & 120 & 43.7 \\
\hline
\end{tabular}

\section{DISCUSSION}

By using the multiplex molecular method, we were were found in infertile male subjects in our study. In able to demonstrate the prevalence rates of $10.9 \%$ for a study by Choe et al (2013) who evaluated 510 urine $\mathrm{CT}, 0.7 \%$ in TV, $2.2 \%$ in $\mathrm{MG}, 7.3 \%$ in UU, $8.0 \%$ in $\mathrm{MH}$ samples from male volunteers in South Korea (using and $32.2 \%$ in UP among females with infertility. A Anyplex ${ }^{\mathrm{TM}} / /$ STI-7 Detection Kit), a higher prevalence few researchers have reported the prevalence rates of CT (11\%), TV (1.0\%), NG (5.9\%) MG (3.1\%), UU among males and females in general population using (13.9\%), MH (3.1\%) and UP (17.1\%) were reported. ${ }^{13}$ the same platform (Anyplex ${ }^{\mathrm{TM}}$ /I STI-7 Detection Kit). The prevalent rates of CT and NG in male cohorts in In a study among 2735 endocervical specimens from the present study is also lower in comparison to male women of childbearing age in Italy by Avolio et al populations who are engaged in high risk sexual (2016), lower prevalence rates of CT (2.6\%), TV behaviour and to those attending genitourinary clinic (0.9\%), MG (0.8\%), UU (6.3\%), MH (6.5\%) and UP in Malaysia. ${ }^{14}$

$(30.9 \%)$ were documented in comparison to our study. 11

Table III: Detection of multiple organisms in positivelytested individuals $(\mathrm{n}=21)$

\begin{tabular}{cccc}
\hline $\begin{array}{c}\text { Detected } \\
\text { organism }\end{array}$ & Total (\%) & Female & Male \\
\hline CT+UP & $6(2.2 \%)$ & $5(3.6 \%)$ & $1(0.8 \%)$ \\
MH+UP & $5(1.8 \%)$ & $4(3.0 \%)$ & $1(0.8 \%)$ \\
UP+UU & $3(1.1 \%)$ & $3(2.2 \%)$ & $0(0.0 \%)$ \\
MH+UU & $2(0.7 \%)$ & $2(1.4 \%)$ & $0(0.0 \%)$ \\
MG+UP & $2(0.7 \%)$ & $2(1.4 \%)$ & $0(0.0 \%)$ \\
CT+TV & $1(0.4 \%)$ & $1(0.8 \%)$ & $0(0.0 \%)$ \\
CT+UP+MH & $1(0.4 \%)$ & $1(0.8 \%)$ & $0(0.0 \%)$ \\
MH+UP+UU & $1(0.4 \%)$ & $0(0.0 \%)$ & $1(0.8 \%)$ \\
\hline Total & $21 / 274(7.7 \%)$ & $19 / 137(13.9 \%)$ & $3 / 137(2.2 \%)$
\end{tabular}

CT- C. trachomatis, MG -M. genitalium, TV-T. vaginalis, UU-U. urealyticum, MH-M. hominis, UP-U. parvum

However, in contrast to the female subjects, lower prevalence rates of $\mathrm{CT}(3.6 \%)$, UU (3.6\%), $\mathrm{MH}(2.2 \%)$, and UP (16.8\%) and 0\% detection for TV, MG, and NG
Among the seven sexually transmitted organisms, studies on Chlamydia trachomatis and Neisseria gonorhoeae have consistently demonstrated the pathogenic effects of these two organisms leading to infertility. Meanwhile, there is limited evidence in the literature to implicate Trichomonas vaginalis, Mycoplasma spp and Ureaplasma spp in infertility. However, the availability of NAATs have paved a new approach to evaluate the role of these organisms in infertility.

\section{Chlamydia trachomatis}

The reported prevalence rates for Chlamydia trachomatis (CT) in those with infertility varies widely depending on the cohort of patients studied, the detection methods used and the geographical region in which the study is conducted. In women, CT 
Table IV: Distribution of symptoms among symptomatic individuals with and without detected organisms

\begin{tabular}{|c|c|c|c|c|c|}
\hline Symptoms & Total $n=24(\%)$ & Female $n=20$ & & Male $n=4$ & \\
\hline & & Positive & Negative & Positive & Negative \\
\hline Pelvic pain only & $7(29 \%)$ & $\begin{array}{c}5 \text { (CT,UP,MH, } \\
\text { MG,UP) }\end{array}$ & 2 & 0 & 0 \\
\hline Dysuria only & $7(29 \%)$ & $1(U P)$ & 2 & 1 (UP) & 3 \\
\hline $\begin{array}{l}\text { Per vaginal } \\
\text { discharge }\end{array}$ & $5(20 \%)$ & $\begin{array}{l}\text { 4(UP,UU+MH, } \\
\text { UP+CT, UP) }\end{array}$ & 1 & 0 & 0 \\
\hline $\begin{array}{l}\text { Pelvic pain with } \\
p / v \text { discharge }\end{array}$ & $3(12.5 \%)$ & $1(U U)$ & 2 & 0 & 0 \\
\hline $\begin{array}{l}\text { Dysuria with } \mathrm{p} / \mathrm{v} \text { dis- } \\
\text { charge }\end{array}$ & $1(4 \%)$ & 0 & 1 & 0 & 0 \\
\hline $\begin{array}{l}\text { Dysuria with pelvic } \\
\text { pain }\end{array}$ & $1(4 \%)$ & 0 & 1 & 0 & 0 \\
\hline
\end{tabular}

CT- C. trachomatis, MG -M. genitalium, TV-T. vaginalis, UU-U. urealyticum, MH-M. hominis,

UP-U. parvum, $\mathrm{p} / \mathrm{v}$ - per vaginal

is a recognised and established cause of tubal infertility. In Malaysia, earlier study in infertile female by Hazlina et al. (2005) using direct immunofluorescence and Chlamydia IgM reported a low prevalence of $4 \% .{ }^{15}$ Yeow et al (2016) used PCR and reported a significantly higher rate of $82 \%$ in infertile women suspected to have bacterial infection. ${ }^{16}$ The present study found $10.9 \%(15 / 137)$ prevalence rate in Malaysian women with infertility. The same prevalence rate $(10.9 \%)$ was also reported by Fernandes et al. (2014) when they study 340 women undergoing assisted reproduction in a public reference service in Brazil. ${ }^{17}$

The low prevalence in comparison to Yeow et al. was most likely due to the difference in inclusion criteria of the subjects. Worldwide, studies in infertile females reported rates ranging from $2.2 \%$ in USA to $32 \%$ in Iran. ${ }^{18-19}$ In male subjects in this present study, the positive rates for $\mathrm{CT}$ was $3.6 \%$; almost similar to rates in Kuwait $(3.9 \%)^{20}$ and slightly higher than rates reported in China (2.58-2.92\%). ${ }^{21}$ Higher prevalence rate among infertile males were reported in Jordan $(4.3 \%)^{22}$ and very high rate in Tunisia (43.3\%). ${ }^{23}$ Other study in Tunisia, Sellami et al. (2014) also reported widespread Chlamydia trachomatis infection among male partners of infertile couple albeit at lower rate $(15.2 \%$ vs $43.3 \%)$. Although both study employed molecular method for detection, the use of quantitative real time PCR in Sellami et al. was most likely more specific than in-house PCRmicrotiter plate hybridization method used in earlier study by Gdoura et al. (2008), thus yielding lower detection of $\mathrm{CT}^{23,24}$

The role of Chlamydia trachomatis in male infertility was studied by many and had yielded conflicting results. Some works showed evidence that CT caused reduction in sperm quality and increased sperm DNA fragmentation in comparison to fertile male ${ }^{24}$ while others report no association between $\mathrm{CT}$ infection and male infertility. ${ }^{25}$ Thus, its role as a direct aetiological agent in male infertility is controversial. Nevertheless, CT infection in male still poses a significant risk as it can be sexually transmitted to their female partners, giving rise to unwanted sequelae as discussed above.

\section{Neisseria gonorrhea}

Similar to Chlamydia trachomatis, Neisseria gonorrhoeae (NG) infection also leads to pelvic inflammatory disease which resulted in tubal infertility, ectopic pregnancy and chronic pelvic pain. Reported prevalence rate in infertile male subjects ranged from $2 \%$ to $6.5 \%$ in various regions. ${ }^{26}$ 
In infertile females, lower prevalence rates of $0.4 \%$ - conflicting. Daly et al. (1989) reported that to $2 \%$ were observed. ${ }^{18,27}$ In this present study we did Trichomonas vaginalis has no effect in sperm motility not find any subjects with $N$. gonorrhoeae, similar to and numbers. ${ }^{30}$ In contrast, Gopalakrishnan et al. the findings by Hazlina et al. (2005). ${ }^{15}$

(1990) described abnormal sperm and decreased sperm motility with reversible effects following

In Malaysia, prevalence rates of gonorrhoea were metronidazole treatment. ${ }^{31}$ Although $T$. vaginalis was mostly reported among subjects at higher risk for HIV not singly isolated in this study, it was detected and other STIs such as commercial sex workers (5.8\%) together with C. trachomatis in one woman $(0.8 \%)$ 28 and male attendees of genitourinary clinic while no man was positive for this organism. (24.2\%). ${ }^{14}$ Prevalence rates data among specific Prevalence rates of TV in infertile groups varies population such as infertile groups are scarce and among countries. Casari et al (2010) studied 952 mostly in female subjects. ${ }^{13}$ The reason for non- female subjects in Italy and found a low prevalence detection of NG in our cohorts could not be ascertain rate in infertile vs fertile women $(0.25 \%$ vs $0.54 \%){ }^{32}$ likely because the risk factors for gonorrhoea and However higher prevalence rates were reported in other STIs were not fully assessed in our Egypt $(14.5 \text { vs } 2.5 \%)^{33}$ and Turkey $(18 \% \text { vs } 0 \%)^{34}$. questionnaire. The participants were only required to state history of STIs and any treatment received. Information on sexual history, sex partner(s) and sexual practices were not attained. Only one female subject gave a history of previous $\mathrm{CT}$ infection and was treated for it. Hence we postulated that nondetection was likely due to reason that the infertile couples were regular lifetime partner, thus risk of STI particularly gonorrhoea is relatively lower. Furthermore, this study was conducted at a tertiary care centre, hence prior testing and treatment may have occurred in the patients, which possibly leads to non-detection of NG. Nevertheless, it remains an important aetiological agent of STI that should be excluded and treated in any sexually active individual.

\section{Trichomonas vaginalis}

Unlike gonorrhoea and Chlamydia infections, trichomoniasis is still considered a sexually transmitted infection of minor importance. Nevertheless, there is growing body of evidence that incriminate its role in increased HIV transmission, development of cervical intraepithelial neoplasia (CIN) and infertility in women. ${ }^{29}$ In males, evidence for the role of trichomoniasis in infertility was

In Malaysia, prevalence rates T. vaginalis of $9.5 \%$ $19.2 \%$ were reported among high risk groups such as commercial sex workers ${ }^{35}$ and female drug abuser. ${ }^{36}$ However, in low risk females, zero prevalence were reported in two studies; among females attending obstetrics and gynaecology clinic (Norhayati et al 2016) ${ }^{37}$ and among female attendees of STI clinic (Amal, 2010). ${ }^{4}$ Amal et al. also reported $0.36 \%$ prevalence were seen in female attending family planning clinic. ${ }^{4}$ Norhayati et al. postulated that low prevalence in Malaysia is likely because the participants enrolled were in a low-risk group, whereby most were married and had one stable sexual partner, also financially stable as housewives or had secure occupation. Another explanation for the low prevalence was the possibility of the women using vaginal washings and antiseptics after coitus with their partners. ${ }^{37}$ These reasons could also explain the low prevalence in this present study.

\section{Mycoplasma genitalium}

Mycoplasma genitalium (MG) is an etiological agent of non-gonococcal urethritis in men. Its role in male infertility was reviewed by Huang et al., (2015) in a meta-analysis from several studies involving 307 men 
with infertility, and they suggested a minimal role for MG in male infertility. ${ }^{38}$ Prevalence studies from Tunisia and Kuwait mostly showed low prevalence from $1.3 \%$ to $4.7 \% .^{39,20}$ No male was found positive for this organism in this present study. In female, the role of $M G$ in female infertility is under much scrutiny. Some reports associated it with cervicitis, pelvic inflammatory disease, preterm birth, spontaneous abortion and infertility. ${ }^{40}$ However, a study among women with tubal infertility did not isolate MG. ${ }^{41} \mathrm{~A}$ meta-analysis looking at role of MG in tre female infertility found an estimated 2.5-fold increased risk of infertility associated with MG, however this increased risk was not statistically oth significant. The same study on the other hand, reports a statistically significant role of $M G$ in cervicitis and PID. ${ }^{42}$ Regardless, this organism was detected more often in cervical swabs (19.6\%) and in peritoneal cavity $(5.8 \%)$ of infertile women compared to healthy fertile women. ${ }^{43}$ The present study found a low prevalence of $M$. genitalium in infertile female (2.2\%). Although prevalence in this study is low, it is an important finding as treatment of individuals with MG urogenital infections will prevent sexual transmissions and likely to reduce the risk of complications including tubal factor infertility. ${ }^{44}$

\section{Mycoplasma hominis}

Mycoplasma hominis and ureaplasmas can be transmitted horizontally and sexually. The colonization rates of $\mathrm{MH}$ in both sexually active men and women varied from zero to $13 \%$ in males and zero to $31 \%$ in females. ${ }^{45}$ Among infertile males, reported prevalence varies from $5 \%$ to $21 \%$ depending on geographical region. ${ }^{20,39}$ In infertile females, reported prevalence ranges from zero to $8.1 \%{ }^{41,46}$

As compared to $M$. genitalium, the evidence of Mycoplasma hominis' (MH) role in male infertility is increasing. A large meta-analysis looking at nine casecontrol studies with 2410 cases and 1223 controls concerning $M$. hominis infection found a significant relationship between $\mathrm{MH}$ and male infertility. ${ }^{38}$ In addition, Ahmadi et al., (2017) noted higher detection of $\mathrm{MH}$ in infertile male $(14.5 \%)$ compared to fertile male (3.6\%), improvement in semen quality after antibiotic treatment and $58 \%$ of the female partners of the infertile group were reported to have successfully become pregnant 4 months after completion of treatment. They concluded that antibiotic therapy improved semen quality and fairly treated the male infertility. ${ }^{47}$ Although these evidences are encouraging, these should be interpreted carefully. Most studies did not include other STIs such as gonorrhoea, and Chlamydia trachomatis and also did not demonstrated that by treating $\mathrm{MH}$, fertility was restored. ${ }^{44}$

Studies of pathogenicity of $\mathrm{MH}$ in females are generally complicated due to its high prevalent in sexually active asymptomatic females, ${ }^{45}$ and also the fact that $\mathrm{MH}$ were often recovered or detected together with other recognized STI organisms such as CT and NG. ${ }^{48}$ Hence, in comparison to male counterparts, literatures studying the role of $\mathrm{MH}$ in female infertility did not found conclusive evidence incriminating $\mathrm{MH}$ in female infertility. ${ }^{41}$

\section{Ureaplasma urealyticum \& Ureaplasma parvum}

In healthy sexually active adults, Ureaplasma urealyticum (UU) and Ureaplasma parvum (UP) are both highly prevalent and are thus considered as commensals of the genitourinary tract. ${ }^{45}$ Due to high colonization rates among both men (3-56\%) and women $(8.5-77 \%)^{45}$, these ureaplasmas have also been evaluated for its relationships with infertility. Many investigators have attempted to determine these organisms as a cause of infertility. Previous studies among infertile males have demonstrated that UU may have an aetiological role in male infertility. It has been shown to adhere to sperm cells, resulting in reduction of sperm motility and 
alterations in cell membrane. ${ }^{50}$ A significant role of UU but not UP was also demonstrated in male infertility. ${ }^{38}$ Other studies however, reported no correlation between male infertility and UU. ${ }^{26}$ The prevalence among infertile males for UU were reported from 10.8-24\%. ${ }^{20,22,39}$ and $2.9-9.6 \%$ for UP. ${ }^{22,39}$ Our findings of $3.6 \%$ prevalence rate for UU is lower than others, while for UP, we report a higher prevalence rate of $16.8 \%$.

Remarkably, both organisms were more commonly isolated from infertile female subjects as compared to fertile women as described by Fenkci et al, 2002 and Kasprzykowska et al., (2013). ${ }^{51-52}$ Kasprzykowska et al. studied the potential pathogenicity of these organisms and demonstrated that the presence of UP and UU in the pouch of Douglas may produce chronic inflammation of upper genital tract of women. This finding showed that colonization in cervicovaginal region can lead to ascending inflammation and infection in the sterile upper reproductive tract subsequently adversely affecting it. Their study also indicated that UP can cause similar asymptomatic infection like UU. Hence, the presence of Ureaplasma spp calls for further scrutiny. In the present study, UP and UU were demonstrated in $32.2 \%$ and $7.3 \%$ respectively. This is comparable to rates of detection in cervical swab reported in Italy (33.2\% UP \& $4.7 \%$ UU $)^{68}$ and in Poland (22.2\% UP, $25.9 \%$ UU)..$^{52}$

\section{Detection of multiple organisms}

Infertility afflicts males and females worldwide. Hence, identifying preventable causes such as sexually transmitted infections should be a priority. The utilization of multiplex PCR method allows rapid detection of culturable and difficult-to-culture sexually transmitted organisms with high sensitivity and throughput. It also has the advantage of detecting co-infection, which was not possible using conventional PCR. In this study, co-infections with two or three organisms were noted. Approximately almost $14 \%$ of women and $2.2 \%$ of men were found to have more than one microorganism. The most common dual detection organisms were between $C$. trachomatis with $U$. parvum $(2.2 \%)$ followed by $M$. hominis with $U$. parvum (1.8\%). Ureaplasma urealyticum and $M$. hominis were both detected in $0.7 \%$ of test subjects, while $C$. trachomatis and $T$. vaginalis were observed in $0.4 \%$. Co-infections of the genital tract have been frequently reported by other researchers. ${ }^{6,52}$

The silent nature of infection by many sexually transmitted organisms was apparent in this study. We found that up to $90 \%$ of the CT, MH, UU and UP infections were asymptomatic. If these infections remain undiagnosed, they might eventually cause adverse effects to the individual, their sexual partners and the public health. Detection of wellestablished STIs such as CT and NG in patients during evaluation for fertility treatment may assist the reproductive doctors to look for tubal and pelvic abnormalities as the possible causes of female infertility. Meanwhile although the evidence for the role of mycoplasmas and ureaplasma in the aetiology of infertility is still inconclusive, the presence of these organisms should not be indeterminately ignored. Further studies showing independent association of genital mycoplasmas and ureaplasmas with PID and infertility (by excluding CT, NG, TV and MG infections in the studied populations) will be valuable to guide the diagnostic approach of sexually transmitted diseases in sexually active adults including the infertile individuals.

\section{LIMITATIONS}

The main limitation of this study is the lack of the control group in fertile subjects to serve as comparison, thus the statistics presented were only descriptive in nature. We also acknowledge the limitation in the method of study by using only one commercial kit, with no comparison to other diagnostic approaches such as culture and/or other 
NAAT-based test available. Nevertheless, the method in this study was chosen after consideration that NAAT in general has been established as superior in performance compared to culture and other nonculture diagnostic methods. ${ }^{44}$

The prevalence of studied organisms in couples with primary and secondary infertility were also not explored in this study due to limitation in data collection. Therefore, future research should address the diagnostics issues in sexually transmitted infections in infertility and its' clinical impact on patient care and management.

\section{CONCLUSION}

Sexually transmitted organisms were detected in one third of men and women planning for fertility evaluation. Chlamydia trachomatis, Mycoplasma hominis, Ureaplasma parvum and Ureaplasma urealyticum were mostly detected in asymptomatic patients. The findings emphasize the need for screening particularly for Chlamydia trachomatis in couples undergoing infertility evaluation. High prevalence rate of Ureaplasma parvum among infertile couples and detection of Ureaplasma urealyticum, Mycoplasma genitalium and Mycoplasma hominis should be scrutinized further to clarify their role whether simply being innocent colonizers or actual pathogens in causing male and female infertility.

\section{CONFLICT OF INTEREST}

We declare that we do not have any conflict of interest when performing this study.

\section{ACKNOWLEDGEMENT}

The authors would like to thank the volunteers and nurses at the Reproductive Centre UKM Medical Centre for their cooperation and assistance. This study is supported by the Geran Galakan Penyelidik
Muda 028/2013 from Universiti Kebangsaan

Malaysia.

\section{REFERENCES}

1. Detels R, Green AM, Klausner JD et al. The Incidence and Correlates of Symptomatic and Asymptomatic Chlamydia trachomatis and Neisseria gonorrhoeae Infections in Selected Populations in Five Countries. Sex Transm Dis. 2011; 38(6): 503-509.

2. Hafner LM. Pathogenesis of Fallopian tube damage caused by Chlamydia trachomatis infections. Contraception, 2015; 92(2):108115.

3. Edwards JL \& Apicella MA. The molecular mechanisms used by Neisseria gonorrhoeae to initiate infection differ between men and women. Clin. Microbiol. Rev, 2004;17: 965981.

4. Amal RN, Aisah MY, Fatmah MS, Hayati MI. Trichomoniasis in cosmopolitan Malaysia: is it under control or is it under diagnosed? Southeast Asian J Trop Med Public Health. 2010 Nov;41(6):1312-5.

5. Menezes CB, Frasson AP, \& Tasca T. Trichomoniasis - are we giving the deserved attention to the most common non-viral sexually transmitted disease worldwide? Microbial Cell, 2016; 3(9): 404-419.

6. Rodrigues MM, Fernandes PA, Haddad JP, et al. Frequency of Chlamydia trachomatis, Neisseria gonorrhoeae, Mycoplasma genitalium, Mycoplasma hominis and Ureaplasma species in cervical samples. J Obstet Gynaecol,2011;31 (3):237-41.

7. Taylor-Robinson D, Lamont R. Mycoplasmas in pregnancy. Br J Obstet Gynaecol, 2011 ; 118:164-174

8. Gimenes F, Souza RP, Bento JC, Teixeira JJ, Maria-Engler SS, Bonini MG, Consolaro ME. Male infertility: a public health issue caused by sexually transmitted pathogens. Nat Rev 
Urol. 2014 Dec;11(12):672-87.

9. van Oostrum N, De Sutter P, Meys J, Verstraelen H.Risks associated with bacterial vaginosis in infertility patients: a systematic review and meta-analysis. Hum Reprod. 2013 Jul; 28(7):1809-15.

10. Mahony J, Chong S, Jang D, et al. Urine Specimens from Pregnant and Nonpregnant Women Inhibitory to Amplification of Chlamydia trachomatisNucleic Acid by PCR, Ligase Chain Reaction, and Transcription-Mediated Amplification: Identification of Urinary Substances Associated with Inhibition and Removal of Inhibitory Activity. Journal of Clinical Microbiology. 1998;36(11):3122-3126.

11. Avolio M, Modolo ML, Stano P, De Rosa R, Camporese A. Molecular evaluation of 7 sexually transmissible microorganisms in symptomatic and asymptomatic Italian childbearing age women: is Ureaplasma parvum a real innocent bystander?. Microbiologia Medica, [S.l.], v. 31, n. 3, Oct. 2016.

12. Landis JR \& Koch GG. The measurement of observer agreement for categorical data. Biometrics. 1977 Mar; 33(1):159-74.

13. HS Choe, DS Lee, SJ Lee. Performance of AnyplexTM II multiplex real-time PCR for the diagnosis of seven sexually transmitted infections: comparison with currently available methods. Int J Infect Dis 2013;17:1134-40.

14. Norashikin S, Gangaram HB, Suraiya H. Prevalence of Chlamydia trachomatis in GenitoUrinary Medicine Clinic, Hospital Kuala Lumpur: A 5-year Retrospective analysis. Malaysian Journal of dermatology. 2007;20:101-104

15. Hazlina NHN, Zuky NA, Johari MR, Senik N. A study on common sexually transmitted disease infection in infertile female attending to Infertility Clinic in HUSM, Kota Bharu, Kelantan. International Medical Journal. 2005;12(Issue 3): 205-211.
16. Yeow TC, Wong WF, Sabet NS, et al. Prevalence of plasmid-bearing and plasmidfree Chlamydia trachomatis infection among women who visited obstetrics and gynecology clinics in Malaysia. BMC Microbiology. 2016;16:45. doi:10.1186/s12866-016-0671-1.

17. Fernandes LB, Arruda JT, Approbato MS \& García-Zapata MT. (Chlamydia trachomatis and Neisseria gonorrhoeae infection: factors associated with infertility in women treated at a human reproduction public service. Revista Brasileira de Ginecologia e Obstetrícia, 2014. 36(8), 353-358. [Portuguese].

18. Imudia AN, Detti L, Puscheck EE, Yelian FD, Diamond MP. The prevalence of Ureaplasma urealyticum, Mycoplasma hominis, Chlamydia trachomatis and Neisseria gonorrhoeae infections and the rubella status of patients undergoing an initial infertility evaluation.J.Assist.Reprod.Genet, 2008;25:4346.

19. Marashi SMA, Moulana Z, Fooladi AAI, Karim MM. Comparison of Genital Chlamydia trachomatis Infection Incidence Between Women With Infertility and Healthy Women in Iran Using PCR and Immunofluorescence Methods. Jundishapur J Microbiol. 2014.7 (4):e9450.

20. Al-Sweih NA, Al-Fadli AH, Omu AE, Rotimi VO. Prevalence of Chlamydia trachomatis, Mycoplasma hominis, Mycoplasma genitalium, and Ureaplasma urealyticum infections and seminal quality in infertile and fertile men in Kuwait. J. Androl, 2012; 33, 1323-1329.

21. Liu J, Wang Q, Ji X, Guo S, Dai Y, Zhang Z, Jia L, Shi Y, Tai S, Lee Y. Prevalence of Ureaplasma urealyticum, Mycoplasma hominis, Chlamydia trachomatis infections, and semen quality in infertile and fertile men in China. Urology. 2014 Apr;83(4):795-9.

22. Abusarah EA, Awwad ZM, Charvalos E, Shehabi. Molecular detection of potential 
sexually transmitted pathogens in semen and urine specimens of infertile and fertile males. Diagn.Microbiol.Infect.Dis, 2013;77:283-286.

23. Gdoura R, Kchaou W, Ammar-Keskes L, Chakroun N, Sellemi A, Znazen A, Rebai T, Hammami A. Assessment of Chlamydia trachomatis, Ureaplasma urealyticum, Ureaplasma parvum, Mycoplasma hominis, and Mycoplasma genitalium in semen and first void urine specimens of asymptomatic male partners of infertile couples. J Androl. 2008 Mar-Apr;29 (2):198-206.

24. Sellami H, Znazen A, Sellami A, Mnif H, Louati N.. Molecular Detection of Chlamydia trachomatis and Other Sexually Transmitted Bacteria in Semen of Male Partners of Infertile Couples in Tunisia: The Effect on Semen Parameters and Spermatozoa Apoptosis Markers. PLoS ONE,2014;9(7)

25. Krause W\& Bohring C. Male infertility and genital chlamydial infection: victim or perpetrator? Andrologia, 2003; Aug; Vol. 35 (4), pp. 209-16

26. Karimian R, Roghanian R, Etemadifar Z. Study of association between male infertility and Neisseria gonorrhoeae and Ureaplasma urealyticum infection. Iran J Med Microbiol. 2016; 10 (3) :11-18

27. Elkayal N, Mahmoud N and Abdalla S. Detection of Chlamydia trachomatis and Neisseria gonorrhoeae in Egyptian Women Suffering from Infertility. Advances in Microbiology, 2015;5:769-779.

28. Wickersham JA, Gibson BA, Bazazi AR, Pillai V, Pedersen CJ, Meyer JP, El-Bassel N, Mayer KH, Kamarulzaman A, Altice FL. Prevalence of Human Immunodeficiency Virus and Sexually Transmitted Infections Among Cisgender and Transgender Women Sex Workers in Greater Kuala Lumpur, Malaysia: Results From a Respondent-Driven Sampling Study. Sex Transm Dis. 2017 Nov;44(11):663-670.
29. Soper D. Trichomoniasis: under control or undercontrolled? Am. J. Obstet. Gynecol, 2004;190, 281-290

30. Daly JJ, Sherman JK, Green L, Hostetler TL. Survival of Trichomonas vaginalis in human semen. Genitourin Med, 1989;65:106-108.

31. Gopalkrishnan K, Hinduja IN, Kumar TC. Semen characteristics of asymptomatic males affected by Trichomonas vaginalis. J In Vitro Fert Embryo Transf. 1990;7:165-167.

32. Casari E, Ferrario A, Morenghi E, Montanelli A. Gardnerella, Trichomonas vaginalis, Candida, Chlamydia trachomatis, Mycoplasma hominis and Ureaplasma urealyticum the genital discharge of symptomatic fertile and asymptomatic infertile women. New Microbiol, 2010. 33:69-76.

33. El-Shazly AM, El-Naggar HM, Soliman M, ElNegeri M, El-Nemr HE, Handousa AE, Morsy TA. A study on Trichomoniasis vaginalis and female infertility. J Egypt Soc Parasitol. 2001 Aug;31 (2):545-53.

34. Kaya, Ö., Silfeler, D., Kurt, R., Gözükarad, I., Yengil, E., \& Bayramoğlu, N. (2017). Investigation of the presence of Trichomonas vaginalis in infertile Turkish women, Asian Biomedicine, 9(5), 659-663.

35. Ramachandran S, Ngeow SF. The prevalence of STD among prostitutes in Malaysia. Genitourin Med, 66 (1990), pp. 334-336

36. Nordin RB, Isa AR, Abdullah MR. Prevalence of Sexually Transmitted Diseases Among New Female Drug Abusers in a Rehabilitation Centre. The Malaysian Journal of Medical Sciences: MJMS. 2001;8(2):9-13.

37. Norhayati M, Nor Liyana I, Phoy CC et al. Trichomonas vaginalis infection in a low-risk women attended in Obstetrics and Gynaecology Clinic, Universiti Kebangsaan Malaysia Medical Centre. Asian Pacific Journal of Tropical Biomedicine, Volume 6, Issue 8, 2016; 702-705. 
38. Huang C, Zhu HL, Xu KR, Wang SY, Fan LQ, Zhu WB. Mycoplasma and ureaplasma infection and male infertility: a systematic review and meta -analysis. Andrology, 2015;3: 809-816. doi:10.1111/andr.12078

39. Gdoura R, Kchaou W, Ammar-Keskes L, Chakroun N, Znazen A, et al.. Assessment of Chlamydia trachomatis, Ureaplasma urealyticum, Ureaplasma parvum, Mycoplasma hominis and Mycoplasma genitalium in semen and first void urine specimens of asymptomatic male partners of infertile couples. J Androl, 2008; 29: 198-206.

40. Svenstrup HF, Fedder J, Kristoffersen SE et al. Mycoplasma genitalium, Chlamydia trachomatis, and tubal factor infertility-a prospective study. Fertil Steril, 2008; 90:513520

41. Costoya A, Morales F, Borda P, et al. Mycoplasmateceae species are not found in Fallopian tubes of women with tubo-peritoneal infertility. Braz J Infect. 201216:273-278.

42. Lis R, Rowhani-Rahbar A, Manhart LE. Mycoplasma genitalium infection and female reproductive tract disease: a meta-analysis. Clin Infect Dis. 2015 Aug 1;61(3):418-26.

43. Grześko J, Elias M, Maczyńska B, Kasprzykowska U, Ttaczała M, Goluda M. Occurrence of Mycoplasma genitalium in fertile and infertile women. Fertil Steril, 2009.91:2376-2380.

44. Jensen JS, Cusini M, Gomberg M, Moi H. 2016 European guideline on Mycoplasma genitalium infections. J Eur Acad Dermatol Venereol. 2016 Oct;30(10):1650-1656.

45. McCormack WM, Rosner B, Alpert S, et al. Vaginal colonization with Mycoplasma hominis and Ureaplasma urealyticum. Sex Transm Dis 1986; 134: 67-70

46. Sleha R, Boštíková V, Hampl R, Salavec M, Halada $P$, Štěpán $M$, Novotná Š, Kukla R, Slehová E, Kacerovský M, Boštík P. Prevalence of Mycoplasma hominis and Ureaplasma urealyticum in women undergoing an initial infertility evaluation. Epidemiol Mikrobiol Imunol. Fall 2016;65(4):232-237.

47. Ahmadi MH, Mirsalehian A, Gilani MAS, Bahador A, \& Talebi M. Asymptomatic Infection With Mycoplasma hominis Negatively Affects Semen Parameters and Leads to Male Infertility as Confirmed by Improved Semen Parameters After Antibiotic Treatment. Urology, 2017;100, 97 102.

48. Kilic D, Basar MM, Kaygusuz S, Yilmaz E, Basar $\mathrm{H}$, Batislam E. Prevalence and treatment of Chlamydia trachomatis, Ureaplasma urealyticum, and Mycoplasma hominis in patients with non-gonococcal urethritis. Jpn J Infect Dis. 2004 Feb;57(1):17-20.

49. Khan J \& Farzand R. Prevalence of Mycoplasma hominis and Ureaplasma urealyticum among women with unexplained infertility, with and without vaginitis and cervicitis. Afr J Micobiol Res. 2011;5(8):861-4.

50. Núñez-Calonge R, Caballero $P$, Redondo $C$, et al: Ureaplasma urealyticum reduces motility and induces membrane alterations in human spermatozoa. Hum Reprod 1998, 13: 2756 -2761.

51. Fenkci V, Yilmazer M, Aktepe OC. Have Ureaplasma urealyticum and Mycoplasma hominis infections any significant effect on women fertility? Infez Med. 2002 Dec;10(4):2203.

52. Kasprzykowska U, Elias J, Elias M, Mączyńska B, \& Sobieszczańska BM. (2014). Erratum to: Colonization of the lower urogenital tract with Ureaplasma parvum can cause asymptomatic infection of the upper reproductive system in women: a preliminary study. Archives of Gynecology and Obstetrics, 289, 1135. http:// doi.org/10.1007/s00404-013-3140-1 